\title{
Selection of the most suitable life extension strategy for ageing offshore assets using a life-cycle cost-benefit analysis approach
}

Isaac Animah, Mahmood Shafiee, Nigel Simms, John Ahmet Erkoyuncu, Jhareswar Maiti

\begin{abstract}
Purpose - A substantial number of production assets in the offshore oil and gas industry are facing operation beyond their anticipated design life, thus necessitating a service life extension program in the future. Selection of the most suitable strategy among a wide range of potential options to extend the lifetime of equipment (e.g. re-using, reconditioning, remanufacturing, refurbishing and adding on safety/process control measures) remains a challenging task that involves several technical, economic and organisational complexities. In order to tackle this challenge, it is crucial to develop analytical tools and methods capable of evaluating and prioritizing end-of-life strategies with respect to their associated costs and quantifiable benefits.
\end{abstract}

Design/methodology/approach - This paper presents a life-cycle cost-benefit (LCCB) analysis approach to identify the most suitable life extension strategy for ageing offshore assets by taking into account all the capital, installation, operational, maintenance and risk expenditures during the extended phase of operation. The potential of the proposed methodology is demonstrated through a case study involving a three-phase separator vessel which was constructed in the mid-1970s.

Findings - The results from the application case indicate that the capital expenditure (CapEx) accounts for the largest portion of life cycle cost for the replacement strategy, while risk expenditure (RiskEtablx) is the major contributor to costs associated with life extension. A sensitivity analysis is also conducted to identify factors having the greatest impact on the optimum life extension solution, including oil price, production rate, and money interest rate.

Practical implications - In the past, the decisions about life extension or replacement of inservice equipment were often made in a qualitative way based on experience and judgment of engineers and inspectors. This study presents a "quantitative" framework to evaluate and compare the costs, benefits, and risks associated with life extension strategies and subsequently to select the best strategy based on benefit/cost ratios.

Originality/value - To the best of authors' knowledge, no studies before have applied life cycle assessment and cost-benefit analysis methods to prioritize the potential life extension strategies in the oil and gas industry sector. The proposed approach not only assists decision makers in selecting the most suitable life extension strategy but also helps duty holders reduce the costs corresponding to life extension execution.

Keywords Life extension, life cycle assessment, cost-benefit analysis, offshore assets, capital expenditure, risk expenditure

Paper type Research paper 


\section{Introduction}

The number of ageing assets such as platforms, floating production storage and offloading (FPSO), subsea pipelines and risers in the offshore oil and gas industry has increased globally in recent years. According to Wintle and Sharp (2008), a significant number of installations in the Norwegian Continental Shelf (NCS) and the United Kingdom Continental Shelf (UKCS) are facing operation beyond their original design life of 20 to 30 years. Stacey et al. (2008) also reported that almost $50 \%$ of the fixed installations in the UKCS have exceeded their anticipated design life. Figure 1 shows a histogram of the number of offshore oil and gas facilities installed in the NCS and UKCS against their age in years. As can be seen, nearly $21 \%$ of the total number of installations are over 30 years old, with some even as old as 50 years. Tveit et al. (2014) predicted that this trend would likely to continue in the future since majority of the offshore oil and gas facilities are reaching their end-of-life period.

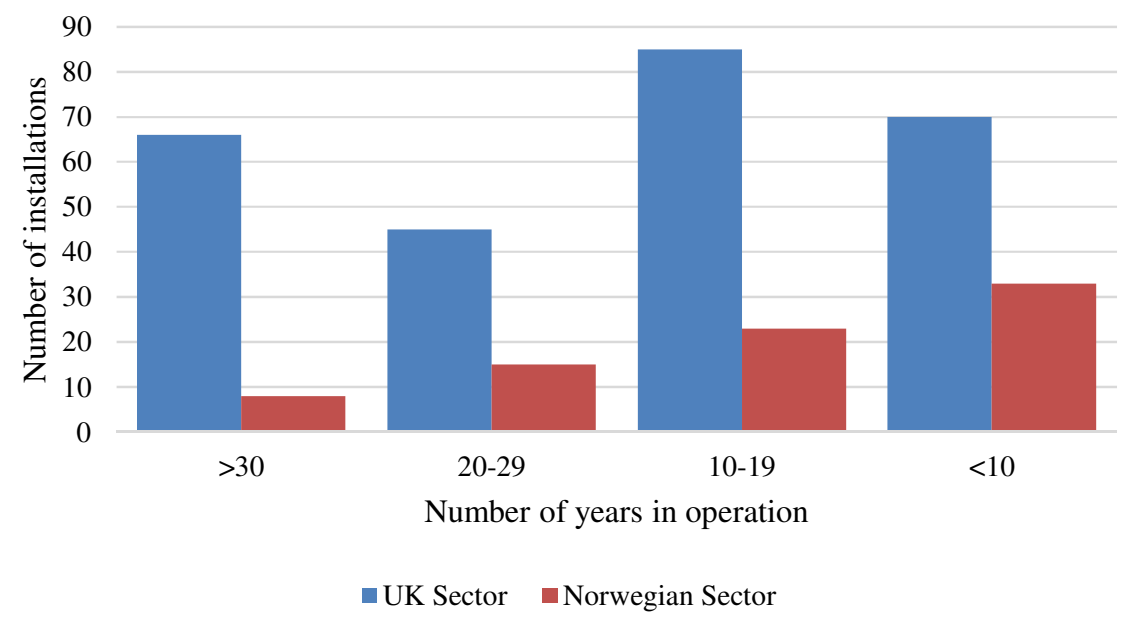

Figure 1. Operational age of offshore installations in the UK and Norwegian sectors of the North Sea (Ersdal, 2005).

With the increasing concern for safety, efficacy, costs, and social and environmental issues, the extension of service life of critical assets has been of great interest to oil and gas field owners, operators, investors and developers (Palkar and Markeset, 2012; Shafiee and Animah, 2017). In the UKCS, the requirements for life extension are identified by the offshore energy division within the Health and Safety Executive (HSE) (for more see http://www.hse.gov.uk/offshore/). Two HSE programmes, namely KP3: asset integrity (HSE, 2009) and KP4: ageing and life extension (HSE, 2012) have been developed to address issues relating to asset ageing and life extension in the UK's offshore oil and gas industry. These HSE programmes concluded that some industries have demonstrated considerable potential for saving investment costs by implementing life extension programs. However, in order to meet the life extension requirements in the long-term, duty holders must ensure that their integrity plans anticipate and manage the effects of equipment and infrastructure degradation as well as their associated consequences during the extended period of operation.

The life extension requirements and activities in Norway are under the control of Petroleum Safety Authority (PSA) (see http://www.psa.no/). PSA is responsible for issuing 
licence, ensuring standardisation, developing life extension guidelines and building a knowledge base of good practices. PSA has recently published a comprehensive report to address issues of ageing assessment and life extension in the offshore oil and gas industry (Hokstad et al., 2010). NORSOK N-006 (2009) discusses how to assess the integrity of existing load-bearing structures for life extension purpose. Furthermore, two standards of NORSOK Y-002 (2010) and NORSOK U-009 (2011) were developed for life extension management of, respectively, transportation systems (i.e. pipelines) and subsea systems (e.g. Christmas trees, manifolds).

In spite of availability of the above-noted useful, important and advantageous guidelines, the decisions regarding life extension of offshore oil and gas assets are still, in practice, made based on experience and judgment of engineers and inspectors (Brandt and Mohd Sarif, 2013; Animah and Shafiee, 2017). These qualitative assessments may lead to inaccurate conclusion or misleading recommendations to asset stakeholders. Life extension decision-making for industrial equipment consists of identification, evaluation and selection of the most suitable strategy among a range of potential end-of-life options such as recycling, reconditioning, remanufacturing, refurbishing, etc. (Shafiee et al. 2016). Selecting the most suitable strategy to extend the service life of offshore oil and gas assets is a relatively challenging task due to lack of proper analytical/comparative methodologies and also incompleteness and low accuracy of recorded data. In order to tackle this challenge, it is crucial to develop tools and methods capable of evaluating various end-of-life strategies in terms of their associated costs and quantifiable benefits and then selecting the most suitable solution based on trade-off analysis.

This paper proposes a whole life-cycle cost-benefit (LCCB) analysis model to identify the most suitable life extension strategy for offshore oil and gas assets by taking into account all the capital, installation, operational, maintenance and risk expenditures. This analysis approach provides a "quantitative" framework to help asset managers evaluate and compare the costs, benefits, and risks associated with life extension projects and then select the best strategy based on benefit/cost ratios. To the best of authors' knowledge, no studies before have applied life cycle assessment and cost-benefit analysis methods to prioritize the potential life extension strategies applicable in the oil and gas industry sector. Our developed LCCB methodology not only takes into account capital expenditure (CapEx) and operational expenditure $(\mathrm{OpEx})$ at the design phase of equipment life cycle but also includes all costs associated with renewing, replacing, rehabilitating, refurbishing or restoring assets (i.e., capital maintenance expenditure or CapManEx) as well as fatality, injury, and property damage costs (i.e., risk expenditure or RiskEx). The proposed approach is validated with a case study of a three-phase separator vessel and the results are subsequently discussed and evaluated.

The rest of the paper is organised as follows. Section 2 gives an overview of studies on cost-benefit analysis and life cycle costing approach in the offshore oil and gas industry. Section 3 presents a step-by-step procedure of the proposed method to determine the most suitable life extension strategy. In Section 4, the model is applied to a case study and the optimal actions are selected. A sensitivity analysis is also conducted to investigate the 
influences of different parameters on the resulting solution. Finally, Section 5 concludes the study and suggests topics for future work.

\section{Research background}

\subsection{Cost-benefit analysis (CBA)}

Cost-benefit analysis (CBA), also referred to as benefit-cost analysis (BCA), is an analytical tool used to evaluate projects or investments by comparing the economic benefits and costs of each alternative. In this technique, all costs and benefits associated with an activity over the life time of the project are quantified in monetary terms (Mishan and Quah, 2007). Then, the overall project performance is measured by some indicators such as net present value (NPV), benefit/cost ratio (BCR) and internal rate of return (IRR), thus allowing to compare alternatives (scores) and select the best solution. The benefit/cost ratio is defined as the present value of benefits divided by the present value of costs. An activity is considered worthwhile if the sum of its benefits becomes greater than the sum of its costs or, identically, when the net benefit is positive or benefit/cost ratio is more than 1. In the case when only one activity can be undertaken (because, for example, there are limited budget), then the rule is to choose the activity with the highest benefit/cost ratio.

Generally, the CBA process involves identification of the project alternatives as well as the base case, determination of the potential cost and benefit factors, selection of the economic parameters required for analysis (discount rate, period of analysis, cost of new hardware/software upgrades, etc.), collection of the required data, quantification of the present value of the costs and benefits, evaluation of the benefit/cost ratios and, eventually, selection of the alternative with the highest ratio. This tool has been so far employed to evaluate the feasibility of investment projects within various industry sectors such as nuclear, aerospace, oil and gas, petrochemical, renewable energy, defence, rail transport, shipping, electricity distribution and transmission, etc. As far as application to the offshore oil and gas industry is concerned, CBA is a more powerful technique compared to other economic evaluation techniques. Readers can refer to the following papers for more details: Smith et al. (1997); Willis et al. (1999); Tague and Hollman (2000); Joshi (2003); Islam and Powell (2005); Liu and Ford (2008); Orimo et al. (2012); Guzman and Asgari (2014); Agwu et al. (2015).

\subsection{Life-cycle costing (LCC) in the offshore oil and gas industry}

Life-cycle costing (LCC) is an important economic analysis used for the assessment of total cost of asset ownership with taking into consideration all expenditures over the entire life cycle from the initial investment costs to subsequent maintenance and operating costs through to salvage and resale value. The LCC concept was first developed by the United States' (US) Department of Defense (DoD) in the early 1960s to increase the effectiveness of government procurement operations (Shields and Young 1991; Ghosh et al., 2017). Since then, it has been applied to a wide range of projects across a variety of sectors including transportation, energy, manufacturing and health care. In this section, a brief overview of LCC-studies with application to the offshore oil and gas industry is given. 
Smith and Celant (1995) incorporated the LCC approach to compare the net present value (NPV) of alternative materials for downhole tubing and then selected the most suitable option. Winkel (1996) employed LCC analysis to achieve an optimum mix of materials and equipment during the conceptual phase of the Ekofisk redevelopment project in the Norwegian North Sea. The authors found out that the discount rate and service tubing life were two key variables influencing the decision-making. ISO 15663-1 (2000), ISO 15663-2 (2001) and ISO 15663-3 (2001) provide guidance on the use of life-cycle costing techniques within the petroleum and natural gas industry. Paula et al. (2001) investigated efficient ways to improve the design of subsea manifolds and presented a comparison among different generations of such equipment using the LCC approach. Iwawaki et al. (2002) introduced an activity-based LCC methodology to support the decision-making process for facility management including inspection and maintenance work executions in refinery industry. Vorarat et al. (2004) provided a structural breakdown of cost (SBC) and developed an LCC technique for evaluating and comparing the costs associated with installation of new offshore structures. The model was applied to a water injection pump case study using data stored in SAP (System Application and Product in Data Processing).

Islam and Powell (2005) employed LCC analysis tool to select the most suitable carbon steel for flowline replacement in an oil and gas company in the Middle East. The study was limited to the analysis of four different materials such as carbon steel with inhibitor, in-situ coating, in-situ HDPE linings and corrosion resistance alloys (CRAs). The LCC calculation showed that the use of in-situ HDPE linings was the best option while carbon steel with inhibitors or CRAs were least attractive option from economic perspective. Kayrbekova and Markeset (2008) applied LCC concept to develop operational, maintenance and support services strategies for reduction of the risks. The study further discussed the challenges regarding the application of LCC analysis to operation and maintenance planning of complex offshore oil and gas production facilities in harsh environments. Li et al. (2009) proposed a cost-effective optimum design model to minimize the expected LCC of ice-resistance platforms in Bohai Bay oil field in China. Kayrbekova and Markeset (2010) in a study explored the current practices relating to the use of LCC concept in the Norwegian Continental Shelf (NCS). The study gives details of findings from reviewing different LCC guidelines and interviewing industry experts. Kayrbekova et al. (2011) proposed an activitybased LCC as an alternative to conventional LCC in engineering design and then applied it to a case study in the arctic offshore environment. The results from the case study indicated that activity-based LCC is capable of handling both costs and cash flows, in contrast to conventional LCC approach which deals with cash flows only.

Nam et al. (2011) proposed a new LCC methodology to evaluate offshore process alternatives at the conceptual design stage taking into account risk expenditures. The study demonstrates that LCC can play a key role in selecting the best liquefaction process alternative for floating liquefied natural gas (LNG) production facilities. Ortiz-Volcan and Iskandar (2011) proposed an LCC approach to support selection of suitable production technologies for heavy oil well construction projects. Burlini and Araruna (2013) applied the concept of LCC analysis to waste management programs during the exploration phase of offshore oil and gas projects. The goal of this study was to help companies involved in exploration of oil and gas in Brazil to integrate LCC methodology into waste management 
decision-making in order to comply with current regulatory regime. Wang and Weng (2014) developed a new LCC methodology to evaluate how much reduction of earthquake force could minimize the costs for base-isolated large LNG tanks.

Marten and Gatzen (2014) developed an integrated bottom-up LCC approach to support objective decision making through transparency of cost by oilfield service providers. The approach was used for proposing a cost effective solution to develop a close-loop-rotary steering service for oilfield service provider. Adam and Ghosh (2016) applied LCC model to assists Brunei Shell Petroleum (BSP) to select the most suitable material for design of piping systems based on cost-saving criteria. The study considered three materials namely carbon steel (CS), corrosion resistance alloys (CRA) and flexible composite pipe (FCP) system. FCP was selected as the cost-effective material for the piping system design. Johannknecht et al. (2016) developed a modular and holistic model to analyse and optimise LCC and service availability of drilling systems from conceptual design phase through to deployment. The model was applied to support the development of a drilling tool in order to demonstrate its cost saving potential. The results indicated the approach was fast, easy to use and standardized for high-technology drilling equipment.

As the above review of research indicates, no studies have so far reported the use of life cycle assessment or cost-benefit analysis techniques in identification and evaluation of life extension strategies for ageing offshore assets. In next Section, we propose a whole life-cycle cost-benefit (LCCB) analysis model to select the most economic strategy among potential options to extend the lifetime of offshore assets, namely re-use, retrofit, replace, recondition, remanufacture, refurbish and add-on safety/process control measures).

\section{The proposed approach}

\section{Nomenclature}

$\begin{array}{ll}\beta & \text { shape parameter of Weibull distribution } \\ \eta & \text { scale parameter of Weibull distribution } \\ \lambda_{F_{j}} & \text { annual frequency of fatalities/injuries caused by risk event } j \\ \lambda_{A D_{j}} & \text { annual frequency of asset damage caused by risk event } j \\ \lambda(.) & \text { hazard rate function of the asset failure time } \\ A_{o} & \text { average operational availability of asset } \\ B_{S o}(t) & \text { social benefits associated with a life extension program in year } t \\ B_{o p}(t) & \text { operational benefits associated with a life extension program in year } t \\ B_{e n}(t) & \text { environmental benefits associated with a life extension program in year } t \\ c_{i} & \text { unit cost of a safety/process and hazard control device (sensor) of type } i \text { added onto } \\ C_{A_{j}} & \text { the asset for life extension } \\ C_{A D} & \text { cost associated with asset damage caused by risk event } j \\ C_{\mathrm{CM}} & \text { compensation cost associated with asset damage } \\ C_{F} & \text { cost of corrective maintenance actions per man-days } \\ C_{F_{j}} & \text { compensation cost associated with fatalities/injuries } \\ C_{I N S T} & \text { cost associated with fatalities/injuries caused by risk event } j \\ C_{I N S T}^{D} & \text { installation cost of new hardware/software upgrades for life extension } \\ C_{I N S T}^{l} & \text { cost of asset downtime due to installations for life extension }\end{array}$




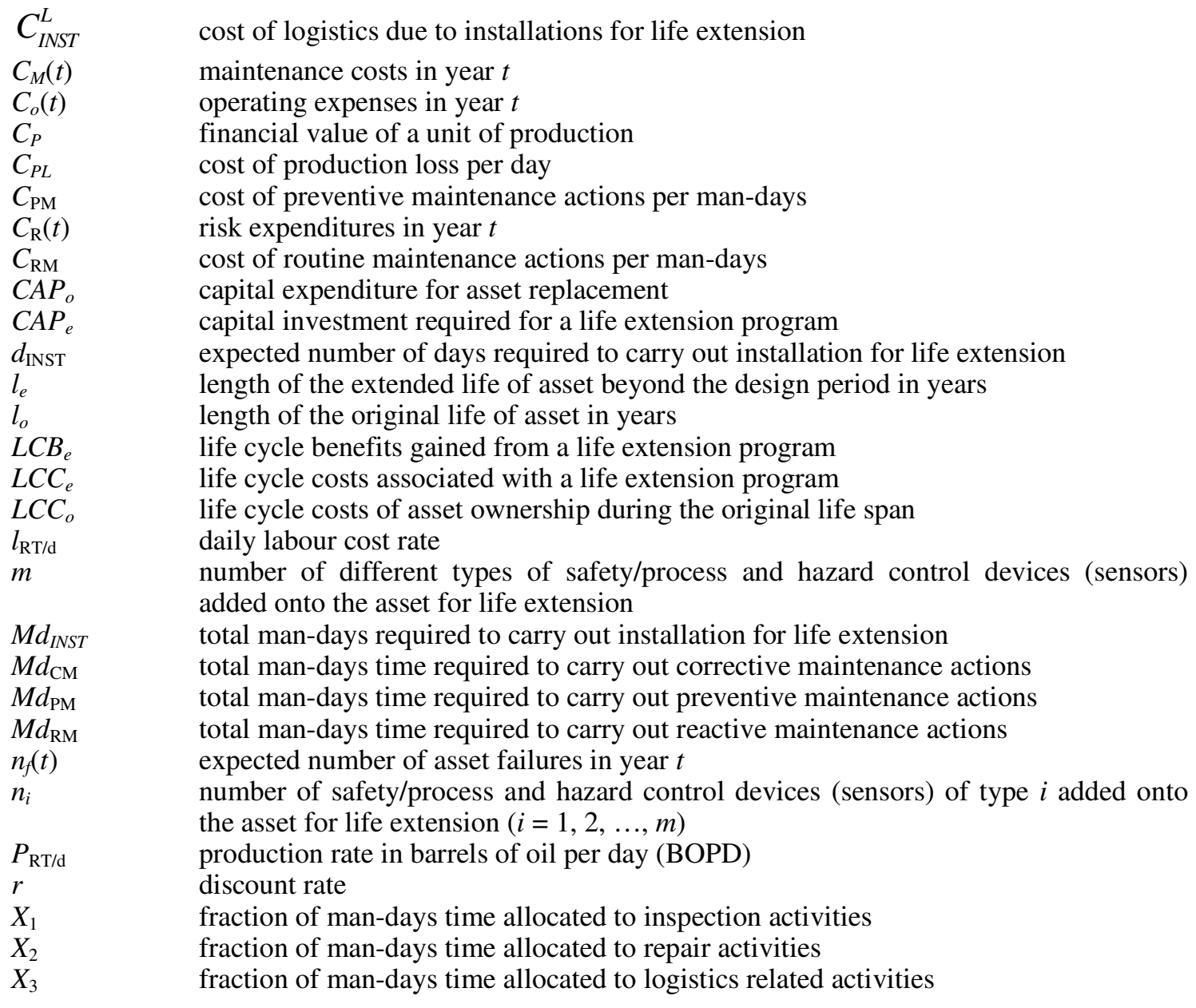

In this section, a step-by-step process of the proposed approach to determine the most suitable life extension strategy for ageing offshore oil and gas assets is given. As shown in Figure 2, the methodology includes four steps as following: definition of goals and constraints, identification of life extension strategies, evaluation of benefits and costs associated with each alternative, and selection of the most suitable strategy with the largest benefit/cost ratio. These steps are explained in more detail as below: 


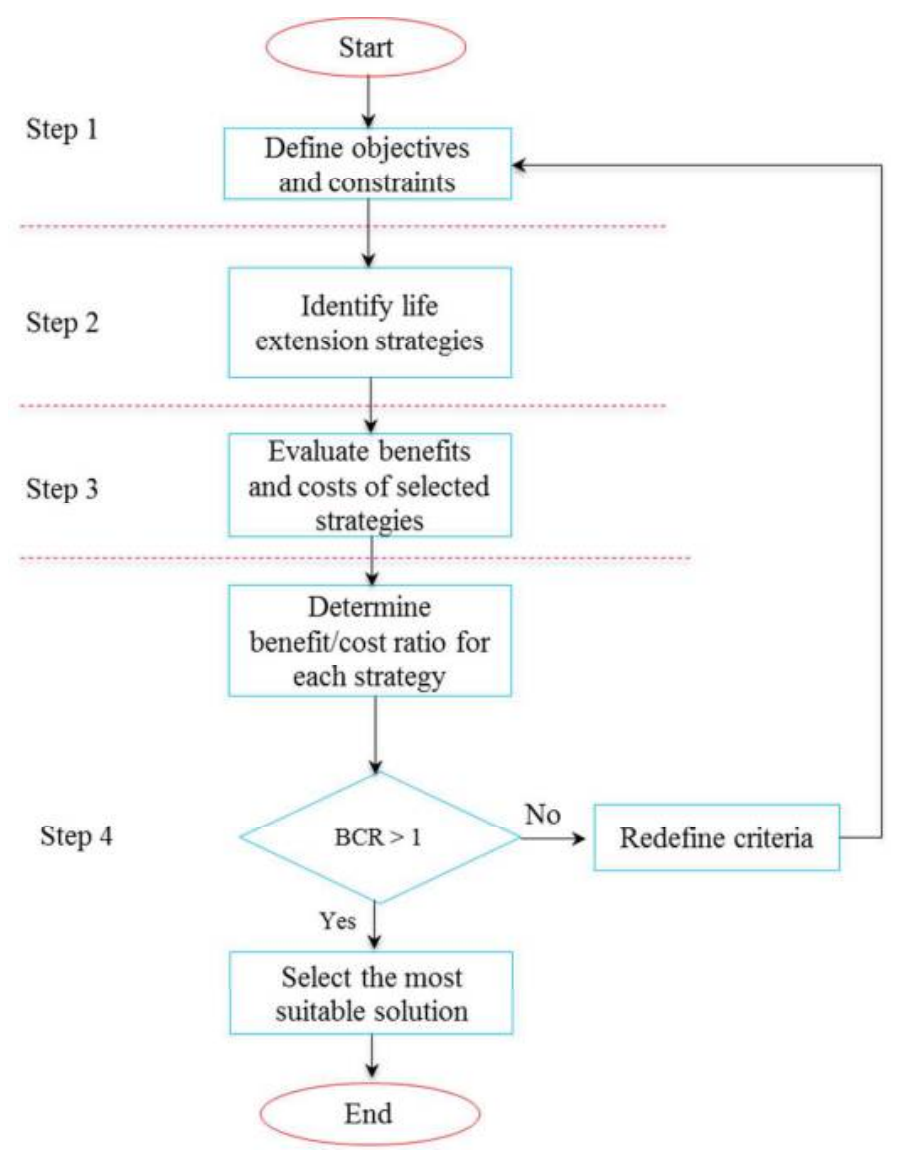

Figure 2. Life extension strategy selection process.

\subsection{Define objectives and constraints}

The first step of the methodology is to define the objectives and constraints under which a life extension program is to be developed. The ultimate goal of extending the service life of assets is to maximize production and improve their overall performance, however, some economic, technical and regulatory constraints may be present in the process (Vaidya and Rausand, 2011). Economic constraints, such as budget constraint will affect the life extension decision making in a way that strategies requiring extensive investment may not be chosen as a longterm solution for equipment lifetime. The budget available for a life extension program can be expressed as a percentage of the capital investment required to acquire the system/component (Tugnoli and Cozzani, 2009). Technical constraints such as limited size, weight, space, nature of production fluid and obsolescence (age of technology) can render some strategies not practical. Changes of regulations and standards in the offshore oil and gas industry may also not permit the use of some life extension strategies. For example, the Atmosphères Explosibles (ATEX) directives 99/92/EC and 94/9/EC legislated by the European Union (EU) and the UK regulation for Prevention of Fire, Explosion and Emergency Response (PFEER) (HSE, 2016) pose a challenge to duty holders when considering life extension strategies for offshore installations.

\subsection{Identify life extension strategies}


In this step, the potential life extension strategies applicable to offshore oil and gas assets are introduced. For this purpose, first, a list of strategies to extend the service life of facilities were identified on the basis of findings from the literature review. Then, those alternatives that were found to be poorly relevant to the offshore oil and gas industry were excluded by the expert panel (composed of original equipment manufacturer (OEM), asset managers, operators, inspectors, safety executives, etc.). Alternative strategies for life extension of offshore oil and gas assets include:

\subsubsection{Reuse}

This strategy includes continuing to use the asset in its current form without any further manufacturing process being involved. It involves leasing the system or selling the system to new owner. Systems with low technological and aesthetic obsolescence are suitable for reuse at the end of life and are often sold on second markets. Re-use is known as an economic driven strategy because no material is used and the associated labour cost is minimum compared to other life extension strategies.

\subsubsection{Retrofit}

Retrofitting is a popular life extension strategy for offshore structures that can result in increased functionality and improved availability. This is the process of replacing old components or equipment on an installation with modern equivalent facilities. It is ideally conducive for equipment and components having large maintenance costs and/or failure rate. One key disadvantage of this strategy is potential service interruptions.

\subsubsection{Replacement}

Replacement involves acquisition and installation of completely new systems in place of existing ones at the end of life. This strategy remains an expensive life extension alternative (Brown and Willis, 2006) and its execution often takes longer time than other strategies. However, it is preferred to other options in situations where system/component becomes obsolete in a short time. For example, electrical systems and control module are mostly subject to the replacement option when reaching end-of-life.

\subsubsection{Reconditioning}

This is the process of improving the condition of used equipment to a satisfactory functional level which is lesser to that of Original Equipment Manufacturer (OEM)'s items (Ijomah et al., 2007). The improved equipment will also have a warranty, but less than that of a newly manufactured equivalent (Shafiee et al., 2011). The strategy is appropriate for systems with low obsolescence, high inherent material failure and easy to assemble and disassemble. It has added value of low of production cost and environmental impact, since components with high failure rate are the only ones remedied. It also has the social benefit of improving the skill and technical knowledge of workforce.

\subsubsection{Remanufacturing}

Remanufacturing is relatively a new strategy used to extend the lifetime of equipment in the offshore oil and gas industry. It is defined as the process of restoring a used item to nearlynew condition equivalent to OEM's standards and specifications (Shafiee et al., 2009; 
Animah et al., 2017). Abbey et al. (2013) and Charter and Gray (2008) also discussed how the remanufacturing could result in reduced cost and usage of materials, reduced workload and staffing, and increased revenue. However, it requires significant time and high investment cost to start the remanufacturing process. It is suitable for systems with major components having high inherent material failure and easy to assemble and disassemble.

\subsubsection{Add-on safety/process control measures}

These strategies involve continuing to use the existing systems but some further safety, process or hazard control measures will be installed to improve the performance of facilities during the extended life of operation. This is mostly applicable to life extension of process equipment.

\subsection{Evaluate benefits and costs of life extension strategies}

According to Brown and Willis (2006), life extension strategies must be examined based on their economic attractiveness and safety. Operating the systems in an economic manner without compromising safety during the extended life phase will require asset managers to carefully evaluate the factors driving benefits and costs of various life extension strategies. In what follows, the benefits and costs of life extension are briefly discussed to supplement the analysis.

\subsubsection{Life extension benefits}

The benefits associated with life extension, according to stakeholders' interests, can be categorized into: (i) social benefits, e.g., increased employment opportunities and labor productivity; (ii) operational benefits, e.g., increased revenue generation and cost-savings by delaying the decommissioning process and (iii) environmental benefits, e.g., reduction in $\mathrm{CO}_{2}$ emissions. Denote by $B_{s o}(t), B_{o p}(t)$ and $B_{e n}(t)$, respectively, the social, operational and environmental benefits associated with a life extension program in year $t$. In order to account for the 'time value' of money, the yearly benefits are discounted to present values by multiplication with a factor equal to the minimum acceptable rate of return (MARR). The MARR is defined as the lowest interest rate at which a project option under consideration remains economically desirable. Then, the life cycle benefits gained from a life extension program, $L C B_{e}$ is given by Eq. (1):

$$
L C B_{e}=\sum_{t=l_{o}}^{l_{o}+l_{e}} \frac{B_{s o}(t)+B_{o p}(t)+B_{e n}(t)}{(1+r)^{t}},
$$

where $r>0$ is the discount rate or MARR, and $l_{o}$ and $l_{e}$ represent respectively the length of the original life and the length of the extended life beyond the design period in years.

\subsubsection{Life extension costs}

The traditional formula for assessment of a system's LCC during the original life span, $L C C_{o}$ is given by Eq. (2) (Fuller and Petersen, 1995):

$$
L C C_{o}=C A P_{o}+\sum_{t=0}^{l_{o}} \frac{C_{o}(t)}{(1+r)^{t}},
$$


where $C A P_{o}$ represents the initial capital expenditures, and $C_{o}(t)$ represents the operating expenses in year $t$.

Based on the literature review conducted as a part of this research, the cost drivers for life extension decision-making were identified as capital cost, installation cost, operating cost, maintenance cost and risk expenditure. Risk related expenses are considered in our proposed life extension decision-making process because there often exists a higher risk of asset failure after reaching the end-of-life due to ageing mechanisms such as corrosion and fatigue, making the asset more vulnerable to hazards such as fire and explosion. In order to incorporate all costs associated with a life extension program, an improved LCC assessment model is proposed in Eq. (3), that is:

$$
L C C_{e}=C A P_{e}+C_{I N S T}+\sum_{t=l_{o}}^{l_{o}+l_{e}} \frac{C_{o}(t)+C_{M}(t)+C_{R}(t)}{(1+r)^{t}},
$$

where $L C C_{e}$ represents the total life cycle cost associated with a life extension program, $C A P_{e}$ represents the capital investment required for a life extension program, $C_{I N S T}$ represents the cost of installation of new hardware/software upgrades for life extension, and $C_{M}(t)$ and $C_{R}(t)$ represent the capital maintenance expenditure (CapManEx) and the risk expenditure (RiskEx) in year $t$ of the extended life, respectively.

- Capital investment for life extension

Among the life extension strategies, add-on safety and add-on process and hazard control measures strategies will require a capital investment to bring the asset into compliance with standards and regulatory requirements. The capital investment required for developing and purchasing safety/process control measures can be calculated using the equation proposed by Khan and Amyotte (2005):

$$
C A P_{e}=\sum_{i=1}^{m} n_{i} c_{i}
$$

where $m$ indicates the number of different types of safety/process and hazard control devices (sensors) added onto the asset, $n_{i}(i=1,2, \ldots, m)$ is the number of devices (sensors) of type $i$ installed on the system for life extension, and $c_{i}$ represents the unit cost of a device (sensor) of type $i$.

- Installation cost for life extension

The cost of installing new hardware/software systems comprises of labor expenses $\left(C_{I N S T}^{l}\right)$, asset downtime cost $\left(C_{I N S T}^{d}\right)$, and logistics related expenditures $\left(C_{I N S T}^{L}\right)$ for life extension. Hence, the installation cost, $C_{I N S T}$ is obtained by summing these three costs as below:

$$
C_{I N S T}=C_{I N S T}^{l}+C_{I N S T}^{d}+C_{I N S T}^{L} .
$$

Logistics expenditure associated with life extension of offshore oil and gas assets includes charges for hiring a barge, ordering spare parts and consumables, transporting crew, 
etc. The labor expenses and the asset downtime cost due to installation for life extension are calculated using Equations (6) and (7), respectively:

$$
\begin{gathered}
C_{I N S T}^{l}=l_{\mathrm{RT} / \mathrm{d}} \times M d_{I N S T}, \\
C_{I N S T}^{D}=C_{P L} \times d_{I N S T},
\end{gathered}
$$

where $l_{\mathrm{RT} / \mathrm{d}}$ is the daily labour rate, $M d_{\text {INST }}$ represents the total man-days required to carry out installation for life extension, $C_{P L}$ is the cost of production loss per day, and $d_{I N S T}$ represents the expected number of days required to carry out installation for life extension. The cost of production loss per day, $C_{P L}$ can be calculated in accordance to the formula contained in ISO 15663-1 (2000) as follows:

$$
C_{P L}=P_{\mathrm{RT} / \mathrm{d}} \times C_{P} \times\left(1-A_{o}\right),
$$

where $P_{\mathrm{RT} / \mathrm{d}}$ is the production rate in barrels of oil per day (BOPD), $C_{P}$ is the financial value of a unit of production, and $A_{o}$ represents the average operational availability of asset which is expressed as the ratio of system uptime to the total time in a given period.

\section{- $\quad$ Maintenance cost during the extended life phase}

Maintenance cost constitutes a significant proportion of the cost of owning and operating an asset. In order to reduce the impact of ageing during the extended life phase and maintain the system performance at high levels, preventive maintenance (PM) activities are designed. Maintenance policy adopted for a life extension program depends on asset failure modes, types of maintenance actions, maintenance lead-times, operating conditions of the asset, cost of maintenance support logistics, etc. In developing our maintenance cost model, three types of maintenance actions are considered, including:

(a) routine maintenance (RM) over the extended life of the asset is carried out with the same frequency as when it is in original life,

(b) corrective maintenance $(\mathrm{CM})$ over the extended life of the asset is carried out to identify and rectify defects so that it can be restored to an operational state after an unexpected failure, and

(c) preventive maintenance (PM) over the extended life of the asset is carried out to control degradation and possible failures in service.

The maintenance costs associated with a life extension program at year $t, C_{M}(t)$ is estimated by Equation (9):

$$
C_{M}(t)=\left[C_{\mathrm{RM}} \times M d_{\mathrm{RM}}\right]+\left[C_{\mathrm{CM}} \times M d_{\mathrm{CM}}(t)\right]+\left[C_{\mathrm{PM}} \times M d_{\mathrm{PM}}\right],
$$

where $C_{\mathrm{RM}}, C_{\mathrm{CM}}$ and $C_{\mathrm{PM}}$ represent the cost of carrying out, respectively, RM, CM and PM actions per man-days, and $M d_{\mathrm{RM}}, M d_{\mathrm{CM}}$ and $M d_{\mathrm{PM}}$ represent the total man-days time required to carry out, respectively RM, CM and PM actions. $M d_{\mathrm{RM}}$ and $M d_{\mathrm{PM}}$ are a function of the number of RM and PM actions planned for every year as well as the number of maintenance technicians required to carry our each action. $M d_{\mathrm{CM}}(t)$ can be expressed as a function of the 
expected number of asset failures in year $t, n_{f}(t)$. Let $\lambda($.) represent the hazard rate function of the asset failure time. Then, the expected number of asset failures over the year $t$ to $t+1$ of the extended life phase is given by:

$$
n_{f}(t)=\int_{t}^{t+1} \lambda(t) d t
$$

For example, for a two-parameter Weibull distribution failure model with shape and scale parameters $\beta$ and $\eta$, the expected number of asset failures at year $t$ is given by:

$$
n_{f}(t)=\int_{t}^{t+1}(\beta / \eta)(t / \eta)^{\beta-1}=\left[(t+1)^{\beta}-t^{\beta}\right] / \eta^{\beta}, t=l_{o}, \ldots, l_{o}+l_{e}-1 .
$$

Denote by $X_{1}, X_{2}$ and $X_{3}$ the fraction of man-days time allocated to, respectively, inspection, repair and logistics related activities, where $X_{1}+X_{2}+X_{3}=1$. Then,

$$
\begin{aligned}
C_{M}(t) & =\left[X_{1} \times C_{\mathrm{RM}}^{I}+X_{2} \times C_{\mathrm{RM}}^{R}+X_{3} \times C_{\mathrm{RM}}^{L}\right] \times M d_{\mathrm{RM}} \\
& +\left[C_{\mathrm{CM}}^{l}+C_{\mathrm{CM}}^{d}+C_{\mathrm{CM}}^{f a b}\right] \times M d_{\mathrm{CM}}+\left[X_{1} \times C_{\mathrm{PM}}^{I}+X_{2} \times C_{\mathrm{PM}}^{R}+X_{3} \times C_{\mathrm{PM}}^{L}\right] \times M d_{\mathrm{PM}},
\end{aligned}
$$

where $C_{\mathrm{RM}}^{l}, C_{\mathrm{RM}}^{R}$ and $C_{\mathrm{RM}}^{L}$ represent respectively the inspection cost, repair cost and logistic expenditures associated with RM actions; $C_{\mathrm{CM}}, C_{\mathrm{CM}}^{d}$ and $C_{\mathrm{CM}}^{f a b}$ represent respectively the labor expenses, downtime cost and fabrication expenditures associated with $\mathrm{CM}$ actions; and $C_{\mathrm{PM}}^{I}$, $C_{\mathrm{PM}}^{R}$ and $C_{\mathrm{PM}}^{L}$ represent respectively the inspection cost, repair cost and logistic expenditures associated with PM actions.

- $\quad$ Risk expenditure during the extended life phase

The risk expenditure (RiskEx) includes the costs incurred by catastrophic accidents such as fire, explosion, release of toxic substances, dropped objects, etc. In this study, the economic impacts of fire and explosion risks in terms of asset losses and human fatalities are considered. One of the main challenges in this regard is to build a model that is capable of accurately quantifying the financial consequences of damage and casualties due to fire and explosion hazards. For this purpose, a risk-cost model as presented in Nam et al. (2011) was used for assessing the risk expenditures associated with the occurrence of major incidents in the offshore oil and gas industry. In this model, the financial losses caused by different hazard scenarios are assessed according to the scales given in Table 1.

Table 1. Cost consequences of the risk events (Nam et al. 2011)

\begin{tabular}{lll}
\hline Severity & Description & Financial loss \\
\hline Catastrophic & Consequences to the whole installation & $100 \%$ of CapEx \\
Major & Consequences to several modules & $50 \%$ of CapEx \\
Significant & Consequences to a single module & $30 \%$ of CapEx \\
Minor & $\begin{array}{l}\text { Consequences limited onto the local area } \\
\text { where the event occurs }\end{array}$ & $10 \%$ of CapEx \\
Fatality & Personal injury and death & 3.6 million Monetary unit \\
\hline
\end{tabular}


Denote by $C_{F}$ and $C_{A D}$ the compensation cost due to fatalities/injuries and asset damage, respectively. In order to estimate these costs the following equations can be used:

$$
\begin{gathered}
C_{F}=\sum_{j=1}^{k} \lambda_{F_{j}} \times C_{F_{j}}, \\
C_{A D}=\sum_{j=1}^{k} \lambda_{A D_{j}} \times C_{A D_{j}},
\end{gathered}
$$

where $k$ is the number of different risk events, $\lambda_{F_{j}}$ and $\lambda_{A D_{j}}$ represent respectively the annual frequency of fatalities/injuries and asset damage caused by the risk event $j(j=1,2, \ldots, k)$, $C_{F_{j}}$ represents the cost associated with fatalities/injuries due to risk event $j$, and $C_{A_{j}}$ represents the cost associated with asset damage caused by the risk event $j$ including cost of repair/replacement, cost of asset breakdown, cost of liability, etc.

\subsection{Select the most suitable life extension solution}

The final step of the life extension decision-making process is to select the most suitable strategy among all alternative strategies. For this purpose, a life extension strategy with the largest benefit/cost ratio (BCR) will be chosen. The BCR for a particular life extension strategy is evaluated as the ratio between the net present value of total inflows (benefits) and the net present value of outflows (costs), i.e.,

$$
\mathrm{BCR}=\frac{L C B_{e}}{L C C_{e}},
$$

where $L C B_{e}$ and $L C C_{e}$ are given in Equations (1) and (3), respectively. The BCR in Equation (15) measures the return for each unit of capital invested in life extension program. A BCR greater than one indicates that the life extension program is economically viable, while a BCR less than one indicates that extending the service life of asset is not beneficial. Among the viable strategies, the strategy with the largest BCR will be chosen as the most desirable.

\section{Application case}

This section presents a case study involving a three-phase separator vessel configured to separate oil, water, and gas components in a crude oil separation module. The separator vessel is located on a platform constructed in the mid-1970s for oil production. Since the time that platform has been commissioned the field has been producing crude oil with low water content. But the production from the reservoirs has steadily changed over the maturity period and it currently produces heavier and more viscous oil with high water content. The separator vessel gathers inlets from three reservoirs with increasing water content. The system consists of a three-phase first stage high-pressure separator with water lines directed to a water treatment system. The wet crude is passed downstream through an intermediate two-phase degassing separator to remove solution gas. The crude oil is then processed through a dehydrator to achieve export specification. The design pressure is 49 barg but it is now operating at a pressure of $25 \mathrm{barg}$. 
The three-phase first stage separator vessel has been designed to the BS-1515 part-1 (1968) specification which is a recommended standard for construction of hydrocarbons pressure vessel. During inspection of the high-pressure separator, pitting corrosion of up to $5 \mathrm{~mm}$ was discovered though corrosion management plan is partially implemented by duty holder. Corrosion rates were predicted to have increased from $0.41 \mathrm{~mm} /$ year to $0.77 \mathrm{~mm} /$ year in the last four years of operation. Based on API 579-1/ASME (2007), a strategy is crucial to minimize the rate of corrosion for high pressure separators ensuring technical integrity for continuous operation.

In what follows, the results obtained from applying the proposed approach are presented and discussed.

\section{- Definition of goals and constraints}

The goal of the project is to select a suitable life extension strategy in order to maintain the technical integrity of a three-phase first stage separator vessel for continuous operation. The constraints for this project include: limited budget, congested spaces and lack of good quality data.

\section{- $\quad$ Identification of life extension strategies}

Among the strategies identified in Section 3.2 for life extension, four alternative strategies were considered for the three-phase separator vessel, namely: $i$ ) replacement, ii) add-on safety measures, iii) add-on process control measures and $i v$ ) add-on safety and process control measures. Lack of good quality data prevented the consideration of remanufacturing and reconditioning strategies for life extension. Table 2 gives details of the alternative strategies chosen for life extension of the separator vessel. As can be seen, the strategy $i v$ is a hybrid between the two strategies $i i$ and $i i i$.

Table 2. Life extension strategies considered for a separator vessel.

\begin{tabular}{|c|l|l|}
\hline No. & \multicolumn{1}{|c|}{ Life extension strategy } & \multicolumn{1}{c|}{ Description } \\
\hline$i$ & Replacement & Subsea separation system \\
\hline$i i$ & Add-on safety measures & Blastwall + Fire-fighting equipment (FFE) \\
\hline$i i i$ & Add-on process control measures & $\mathrm{pH}$ control + pressure control \\
\hline$i v$ & Add-on safety and process control measures & $\mathrm{pH}$ control + Fire-fighting equipment (FFE) \\
\hline
\end{tabular}

- Evaluation of benefits and costs of life extension strategies

At this stage of the proposed approach, the results of the LCC analysis are reported. To evaluate the benefits and costs associated with life extension strategies, the financial and nonfinancial data given in Table 3 were used. The required data for this study were collected from literature, operating company's databases and manufacturer's catalogues and if some information were not available, an independent expert elicitation was performed with the stakeholders.

Table 3. Data for case study 


\begin{tabular}{ll|ll}
\hline \multicolumn{2}{c}{ Non-financial parameters } & \multicolumn{2}{c}{ Financial parameters (monetary unit) } \\
\hline$P_{\mathrm{RT} / \mathrm{d}}$ & $480 \mathrm{BOPD}$ & $C_{\mathrm{RM}}^{l}, C_{\mathrm{PM}}^{l}$ & 2.5 \\
$\beta$ & 4.13 & $C_{\mathrm{RM}}^{R}, C_{\mathrm{PM}}^{R}$ & 75 \\
$\eta$ & 24.28 & $C_{\mathrm{RM}}^{L}, C_{\mathrm{PM}}^{L}$ & 2.5 \\
$M d_{R M}$ & 0.083 & $C_{\mathrm{CM}}$ & 3.5 \\
$M d_{C M}$ & 0.375 & $C_{\mathrm{CM}}^{f a b}$ & 100 \\
$M d_{P M}$ & 0.038 & Cost of product per barrel & 40 \\
$X_{1}$ & 0.5 & Cost of sub-sea separator & $66,000,000$ \\
$X_{2}$ & 0.3 & Cost of pH control & 16,000 \\
$X_{3}$ & 0.2 & Cost of pressure control & 19,900 \\
$r$ & $7 \%$ & Cost of blast wall & 33,100 \\
$l_{e}$ & 5 years & Cost of FFE & 31,900 \\
$I R$ & $25 \%$ & Operating expenditure & $\sim 10 \%$ of annual production cost \\
\hline
\end{tabular}

The relative contribution of each cost element (i.e., CapEx, OpEx, CapManEx, and RiskEx) to total expenditure for each life extension strategy is illustrated in Fig. 3. As the installation of the system was undertaken by contractors, the costs associated with installation were included in the CapEx. As can be seen, the CapEx for replacement of the existing system with a new subsea separator vessel accounts for the largest portion of the life cycle cost making the replacement strategy an expensive life extension alternative. However, the decision to select the replacement strategy over other life extension strategies may be justified by reasons relating to asset obsolescence. For three life extension strategies of addon safety measures, add-on process control measures, and add-on safety and process control measures the RiskEx is the major contributor to total expenditure.

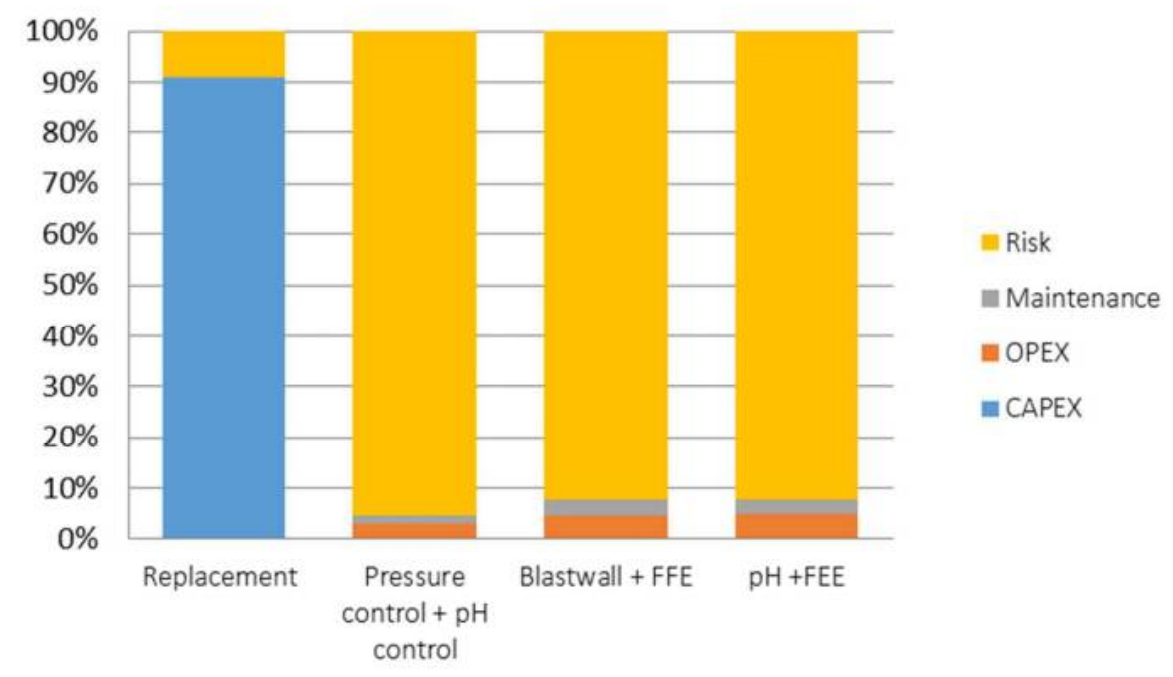

Figure 3. The relative contribution of each cost element to total expenditure of life extension strategies 


\section{- $\quad$ Determination of benefit/cost ratio (BCR)}

Table 4 gives the benefit/cost ratios calculated for four life extension strategies, namely replacement, add-on safety measures (Blastwall + FFE), add-on process control measures $(\mathrm{pH}+$ pressure control), and add-on safety and process control measures ( $\mathrm{pH}$ control + FFE). The BCRs for these four alternatives are respectively $0.26,0.88,0.54$ and 0.89 .

Table 4. BCR for four life extension strategies considered

\begin{tabular}{|l|l|}
\hline \multicolumn{1}{|c|}{ Life extension strategy } & BCR \\
\hline Subsea separation system & 0.26 \\
\hline Blastwall + Fire-fighting equipment (FFE) & 0.88 \\
\hline pH control + pressure control & 0.54 \\
\hline pH control + Fire-fighting equipment (FFE) & 0.89 \\
\hline
\end{tabular}

From Table 4, it is found that none of life extension strategies at a production rate of 480 BOPD and production price of 40 monetary units have a BCR greater than one. It implies that implementation of a life extension program for the separator vessel unit under the abovementioned conditions will not be economically attractive. This is mainly due to the recent sharp decline in the most two influential factors of the oil market, i.e., oil price and production levels (demand).

The LCCB analysis for selecting most suitable life extension strategy required large amount of data from different sources with input data and variables subject to high levels of uncertainty. In order to test the robustness of the approach and evaluate the impact of some key variables, e.g. value of product (oil price), production volumes and discount rate on the optimum life extension solution a sensitivity analysis is conducted. To this aim, at each iteration of the analysis only one parameter is changed while the other parameters remain unchanged. The results from the sensitivity analysis are presented below:

\section{Value of product (oil price)}

The value of product (price of crude oil) is an important determinant factor in economic feasibility of the life extension programs. Figure 4 shows the effect of variation in crude oil prices on benefit/cost ratios associated with four life extension strategies. Around twenty percent increase in crude oil prices will result in that the benefit/cost ratios for two life extension strategies of add-on safety measures (blastwall + FFE) and add-on safety and process control measures $(\mathrm{pH}+\mathrm{FFE}$ ) become greater than one. The process control measures $(\mathrm{pH}$ control + pressure control) will have a BCR greater than 1 when there is about $80 \%$ increase in oil prices. The replacement strategy which has the lowest riskex will be a feasible end-of-life strategy when crude oil prices increase to above 140 monetary unit per barrel. It should be noted that increase in crude oil prices will also impact the production loss cost and thereby, the LCC. 


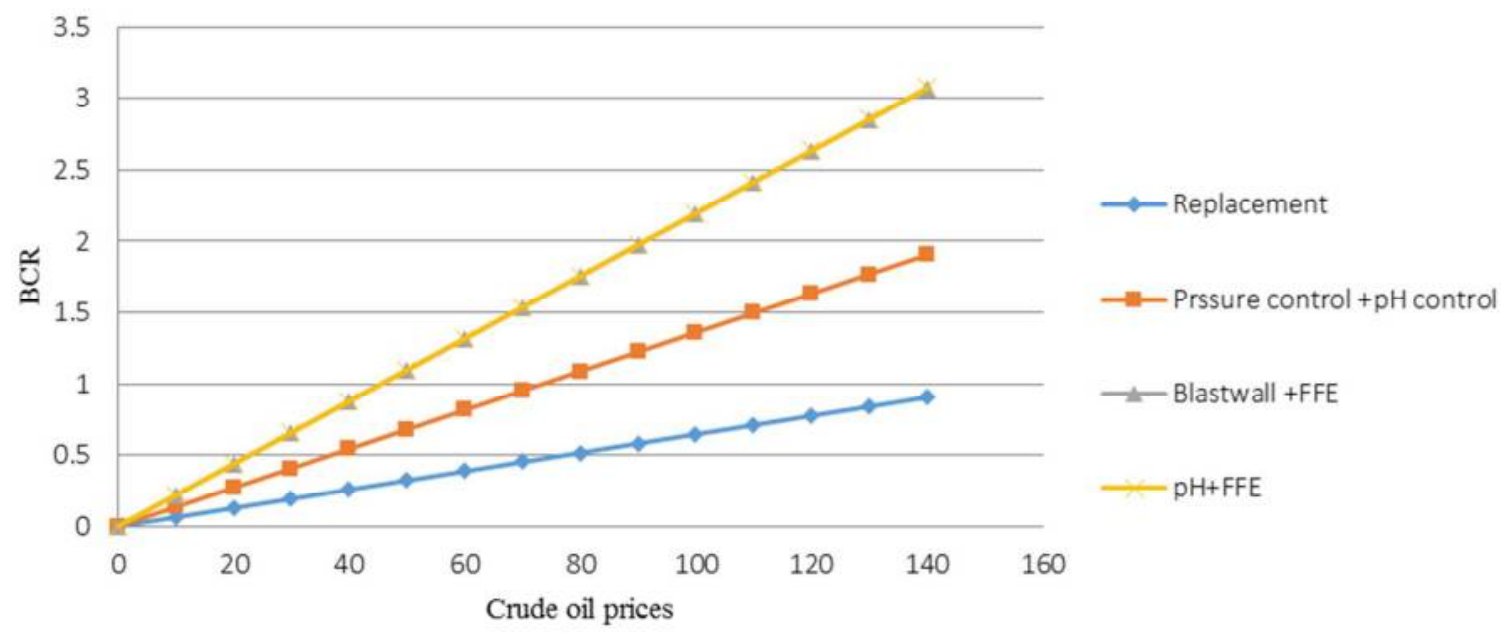

Figure 4. Effect of variation in crude oil price on benefit/cost ratios

\section{Production volume}

Variation of oil production rate with current oil price can significantly influence the life extension decision making. Figure 5 represents the effect of increase in production volume from the oil field on benefit/cost ratios associated with four life extension strategies. Around four-hundred percent increase in production volume at current price of oil per barrel will make the replacement strategy beneficial for life extension. The add-on process control measures $(\mathrm{pH}$ control + pressure control) will be a feasible strategy when there is around $100 \%$ increase in production volume. The other two life extension strategies, i.e., add-on safety (Blaswall + FFE) and add-on safety and process control measure $(\mathrm{pH}+\mathrm{FFE})$ will have a BCR greater than 1 when there is about $25 \%$ increase in production volume.

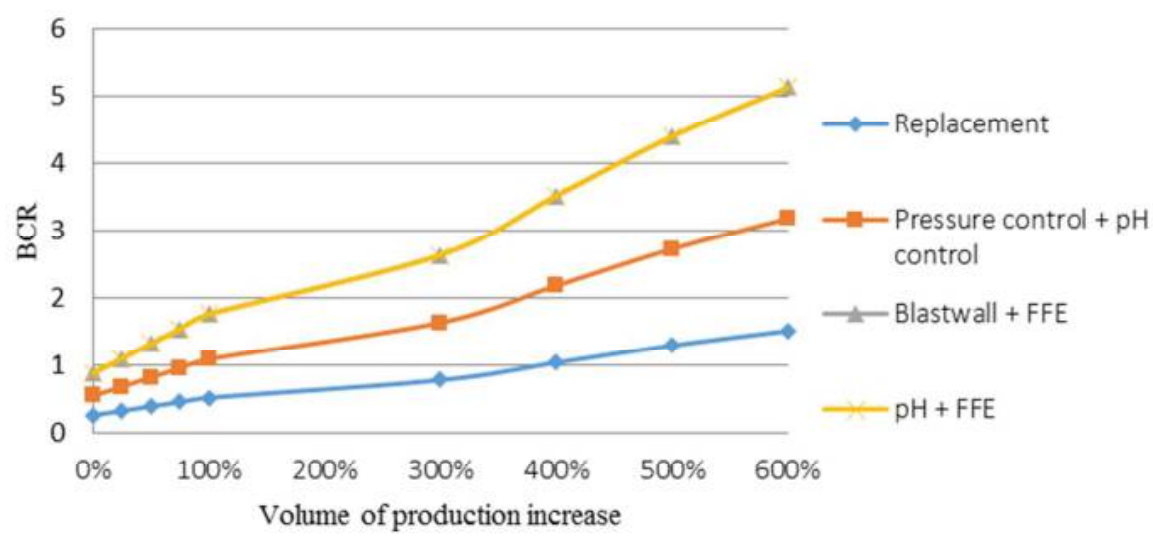

Figure 5. Effect of variation in production volume on benefit/cost ratios

\section{Discount rate}


Variation in discount rate will have relatively large impact on the benefits and costs associated with each life extension strategy. The effect of $20 \%$ decrease in discount rate on LCC is illustrated in Figure 6. As shown, the reduced discount rate results in a considerable reduction in LCC, however it has not changed the benefit/cost ratios significantly. A $20 \%$ decrease in discount rate lowered the LCC for the replacement strategy by about $18.2 \%$.

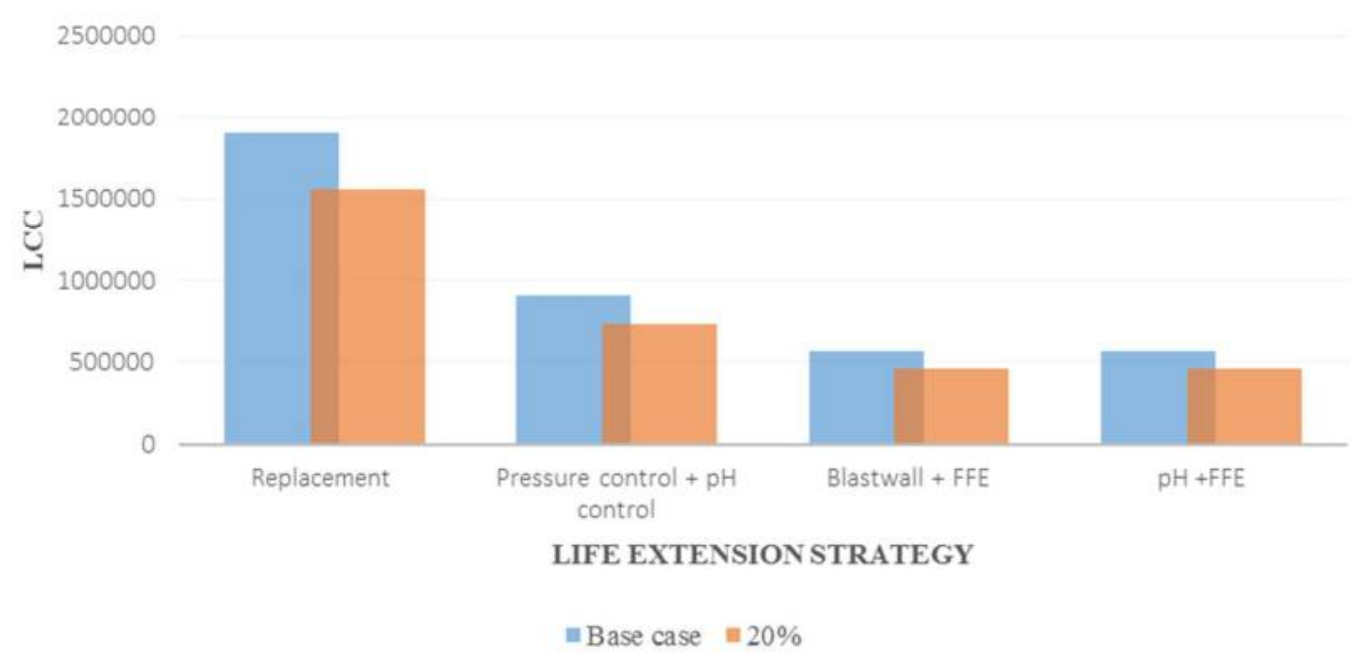

Figure 6. Effect of variation in discount rate on LCC

\section{Conclusions and future work}

Development of a systematic approach for evaluating the suitability of life extension programs for industrial assets remains a challenging task. In this study, a whole life-cycle cost-benefit (LCCB) analysis approach was presented to evaluate and select the most suitable life extension strategy for ageing offshore oil and gas facilities. The proposed approach considers all the costs (including capital, installation, operational, maintenance and risk expenditures) as well as the benefits (including social, operational and environmental) associated with the extended phase of asset operation. To account for the time value of money, the yearly costs/benefits were discounted to present values at an assumed discount rate and lastly, the most suitable life extension strategy with the largest benefit/cost ratio was chosen.

The potential of the methodology was demonstrated through application to a threephase first stage high-pressure separator vessel of a crude oil separation system. The results indicated that risk expenditure incurred during the extended life phase accounts for a significant portion of LCC for the three strategies of add-on blastwall and fire-fighting equipment, add-on $\mathrm{pH}$ control and pressure control, and add-on $\mathrm{pH}$ control and fire-fighting equipment. The sensitivity analysis illustrated that the most important factors influencing viability of life extension programs are: value of product (oil price) and volume of production from the given asset. Also, depending on the duration of life extension program, a small change in interest rate can lead to a significant change in project's LCC. The presented approach not only assists decision makers in selecting the most suitable life extension 
strategy but also helps duty holders reduce the costs corresponding to life extension execution.

The analysis in this study can be extended to incorporate the impact of royalty cost, regulatory licence cost and taxes on life extension strategies. In this study, due to data constraints we limited our analysis to four life extension strategies. However, other life extension strategies such as remanufacturing and reconditioning will also be analysed when the required data becomes available. Similar study can be done by applying the proposed model to support life extension making of safety critical assets within the sectors of renewable energy, rail transport, shipping, electricity distribution and transmission, etc.

\section{Competing Interests}

The authors declare that there is no conflict of interests regarding the publication of this paper.

\section{References}

Abbey, J.D., Guide, V.D.R. and Souza, G.C. (2013). Delayed differentiation for multiple lifecycle products. Production and Operations Management, 22(3), 588-602.

Adam, S. and Ghosh, S. (2016). Application of flexible composite pipe as a cost effective alternative to carbon steel - design experience. In: Offshore Technologv Conference Asia. 22-25 March, Kuala Lumpur, Malaysia, pp. 1-12.

Agwu, O.E., Okon, A.N. and Udoh, F.D. (2015). A comparative study of diesel oil and soybean oil as oil-based drilling mud. Journal of Petroleum Engineering, Article ID 828451, 10 pages.

Animah, I., Shafiee, M., Simms, N. and Tiwari, A. (2017). A multi-stage remanufacturing approach for life extension of safety critical assets. Procedia CIRP, 59, 133-138.

Animah, I. and Shafiee, M. (2017). Condition assessment, remaining useful life prediction and life extension decision making for offshore oil and gas assets. Loss Prevention in the Process Industries, DOI:10.1016/i.iln.2017.04.030.

API 579-1/ASME (2007). FFS-1, Fitness-for Service. American Petroleum Institute \& American Society of Mechanical Engineers, Second Edition.

Bedwell, I., Das, S. and McCall, E. (2015). Life extension of mature facilities through robust engineering and chemistry solutions. Maxoil Solutions, https://www.spe.org/en/ogf/ogf-articledetail/?art=129.

Brandt, H. and Mohd Sarif, S.M. (2013). Life extension of offshore assets - balancing safety \& project economics. In: SPE Asia Pacific Oil \& Gas Conference and Exhibition. 22-24 October, Jakarta, Indonesia, pp. 1-9.

Brown, R.E. and Willis, H.L. (2006). The economics of aging infrastructure. IEEE Power and Energy Magazine, 4(3), 36-43.

BS-1515 part-1 (1968). Specification for fusion welded pressure vessels, British Standards Institution.

Burlini, P.S. and Araruna, J.T. (2013). Life cycle concept (LCC) in the waste management in the O\&G offshore exploration. North Africa Technical Conference and Exhibition. April 15-17, Cairo, Egypt, pp. 1514-1518.

Charter, M. and Gray, C. (2008). Remanufacturing and product design. International Journal of Product Development, 6(3-4), 375-392.

Ersdal, G. (2005). Assessment of existing offshore structures for life extension. PhD Thesis, Department of Mechanical and Structural Engineering and Material Sciences. University of Stavanger, Norway.

Ghosh, C., Maiti, J., Shafiee, M. and Kumaraswamy, K.G. (2017). Reduction of life cycle costs for a contemporary helicopter through improvement of reliability and maintainability parameters. 
International Journal of Ouality \& Reliabilitv Management. DOI:10.1108/JJORM-11-2016$\underline{0199}$.

Guzman, A. and Asgari, B. (2014). A cost-benefit analysis of investing in safety and risk engineering: The case of Oil \& Gas transportation services by pipelines. In: IEEE Portland International Conference on Management of Engineering \& Technology, July 27-31, pp. 1633-1645.

HSE (2009). Key programme 3 - asset integrity: a review of industry's progress. Available at: http://www.hse.gov.uk/offshore/programmereports.htm.

HSE (2012). Key programme 4 - ageing and life extension. Available at: http://www.hse.gov.uk/offshore/ageing.htm.

HSE (2016). Prevention of fire and explosion, and emergency response on offshore installations. Regulations 1995, Approved Code of Practice and guidance L65, Third edition, London, UK, Available at: http://www.hse.gov.uk/fireandexplosion/atex.htm.

Hokstad, P., Håbrekke, S., Johnsen, R. and Sangesland, S. (2010). Ageing and life extension for offshore facilities in general and for specific systems, SINTEF Report A15322, prepared for Petroleum Safety Authority, Stavanger, Norway.

Ijomah, W.L., McMahon, C.A., Hammond, G.P. and Newman, S.T. (2007). Development of design for remanufacturing guidelines to support sustainable manufacturing. Robotics and ComputerIntegrated Manufacturing, 23(6), 712-719.

Islam, M. and Powell, D.E. (2005). Cost benefit analysis of flowline replacement for a major Middle East oil producer. Paper No. 05113, NACE Corrosion Conference, April 3-7, Houston, Texas, USA.

ISO 15663-1 (2000). Petroleum and natural gas industries - Life cycle costing — Part 1: Methodology, Switzerland.

ISO 15663-2 (2001). Petroleum and natural gas industries — Life cycle costing — Part 2: Guidance on application of methodology and calculation methods, Switzerland.

ISO 15663-3 (2001). Petroleum and natural gas industries - Life cycle costing — Part 3: Implementation guidelines, Switzerland.

Iwawaki, H., Kawauchi, Y., Muraki, M., Matsuoka, S. and Evans, D. (2002). Life cycle costing based decision making for reactor effluent air coolers in refineries, NACE Corrosion Conference, April 7-11, Denver, Colorado, USA.

Johannknecht, F., Gatzen, M. M., Hahn, D. and Lachmayer, R. (2016). Holistic life cycle costing approach for different development phases of drilling tools state of the art. In: International Petroleum Technologv Conference. 14-16 November, Bangkok, Thailand, pp. 1-11.

Joshi, S.D. (2003) Cost/benefits of horizontal wells. Society of Petroleum Engineers (SPE), Western Regional Meeting, May 19-24, California, USA.

Kayrbekova, D. and Markeset, T. (2008). Life cycle cost analysis in design of oil and gas production facilities to be used in harsh, remote and sensitive environments. In: Proceedings of the European Safety and Reliability Conference, September 22-25, Valencia, Spain, pp. 29552961.

Kayrbekova, D. and Markeset, T. (2010). Economic decision support for offshore oil and gas production in Arctic conditions: Identifying the needs. In: Proceedings of the European Safety and Reliability Conference, September 5-9, Rhodes, Greece, pp. 1274-1279.

Kayrbekova, D., Markeset, T., \& Ghodrati, B. (2011). Activity-based life cycle cost analysis as an alternative to conventional LCC in engineering design. International Journal of Sustem Assurance Engineering and Management, 2(3), 218-225.

Khan, F.I. and Amyotte, P.R. (2005). I2SI: A comprehensive quantitative tool for inherent safety and cost evaluation. Journal of Loss Prevention in the Process Industries, 18(4-6), 310-326.

Li, G., Zhang, D. and Yue, Q. (2009). Life-cycle cost-effective optimum design of ice-resistant offshore platforms. Journal of Offshore Mechanics and Arctic Engineering 131(3), 031501 (9 pages), DOI:10.1115/1.3124138.

Liu, S. and Ford, J.T. (2008). Cost/benefit analysis of petrophysical data acquisition. In: 49th Annual Logging Symposium, May 25-28, Austin, Texas, USA.

Marten, C. and Gatzen, M. M. (2014). Decreasing operational cost of high performance oilfield services by lifecycle driven trade-offs in development. CIRP Annals - Manufacturing Technologv, 63(1), 29-32. 
Mishan E.J. and Quah, E. (2007). Cost benefit analysis. Fifth edition, Routledge, Oxon, UK.

Nam, K., Chang, D., Chang, K., Rhee, T. and Lee, I.B. (2011) Methodology of life cycle cost with risk expenditure for offshore process at conceptual design stage. Energy, 36(3), 1554-1563.

NORSOK N-006 (2009) Assessment of structural integrity for existing offshore load-bearing structures, Lysaker, Norway.

NORSOK U-009 (2011). Life extension for subsea systems. Lysaker, Norway.

NORSOK Y-002 (2010). Life extension for transportation systems. Lysaker, Norway.

Orimo, Y., De Wilde, J., Ichimaru, Y., Terashima, T. and Van Den Berg, J. (2012) Methodology to determine floating LNG tank capacity by combination of side-by-side down-time simulation and cost/benefit analysis. Offshore Technology Conference, 30 April-3 May, Houston, Texas, USA.

Ortiz-Volcan, J.L. and Iskandar, R.A. (2011). A life cycle approach for assessing production technologies in heavy oil well construction projects. Societv of Petroleum Engineers (SPE). Heavv Oil Conference and Exhibition. December 12-14, Kuwait City, Kuwait.

Palkar. S. and Markeset. T. (2012). Extending the service life span of ageing oil and gas offshore production facilities. Advances in Production Management Svstems. Value Networks: Innovation. Technologies, and Management. Volume 384 of the series IFIP Advances in Information and Communication Technology. pp 213-221.

Paula, M.T.R., Labanca, E.L. and Paulo, C.A.S. (2001). Subsea manifolds design based on life cycle cost. Offshore Technology Conference, 30 April-3 May, Houston, Texas, pp. 33-42.

Shafiee, M., Saidi-Mehrabad, M. and Naini, S.G.J. (2009). Warranty and sustainable improvement of used products through remanufacturing. International Journal of Product Lifecvcle Management 4(1-3), 68-83.

Shafiee, M, Finkelstein, M. and Chukova, S. (2011). Burn-in and imperfect preventive maintenance strategies for warranted products. Proceedings of the Institution of Mechanical Engineers. Part O: Journal of Risk and Reliability 225(2), 211-218.

Shafiee, M., Animah, I. and Simms, N. (2016). Development of a techno-economic framework for life extension decision making of safety critical installations. Loss Prevention in the Process Industries, 44, 299-310.

Shafiee, M and Animah, I. (2017). Life extension decision making of safety critical systems: an overview. Loss Prevention in the Process Industries, 47, 174-188.

Shields, M.D. and Young, S.M. (1991). Managing product life cycle costs: an organizational model. Journal of Cost Management, 5, 39-51.

Smith, L.M. and Celant, M. (1995). Life cycle costing-are duplex stainless steel pipelines the costeffective choice?. In: Offshore Technologv Conference Mav 1-4, Houston, Texas, USA.

Smith, S.J., Tweedie, A.A.P. and Gallivan, J.D. (1997). Evaluating the Performance of Multi-Lateral Producing Wells: Cost Benefits and Potential Risks. In: Latin American and Caribbean Petroleum Engineering Conference, 30 August-3 September, Rio de Janeiro, Brazil pp. 1-21.

Stacey, A., Birkinshaw, M. and Sharp, J.V. (2008). Life extension issues for ageing offshore installations. In: Proceedings of the $27^{\text {th }}$ International Conference on Offshore Mechanics and Arctic Engineering (OMAE). June 15-20, Estoril, Portugal, pp. 199-215.

Tague, J.R. and Hollman, G.F. (2000). Downhole video: a cost/benefit analysis. Societv of Petroleum Engineers (SPE). Western Regional Meeting. June 19-22, California, U.S.A.

Tugnoli, A. and Cozzani, V. (2009). Optimization of safety barriers by staged LOPA. In: Offshore Mediterranean Conference and Exhibition, March 25-27, Ravenna, Italy.

Tveit, E., Sivertsen, H. and Hernæs, S. (2014). Experience from field life extension. In: Offshore Technologv Conference. Mav 5-8, Houston, Texas, USA, pp. 1-8.

Fuller, S.K. and Petersen, S.R (1995) Life-cycle costing manual for the Federal energy management program. U.S. Department of Commerce, National Institute of Standards and Technology.

Vaidya, P. and Rausand, M. (2011). Remaining useful life, technical health, and life extension. Journal of Risk and Reliability, 225(2), 219-231.

Vorarat, S., Al-hajj, A. and Robert, T. (2004). Developing a model to suit life cycle costing analysis for assets in the oil and gas industry. In: SPE Asia Pacific Conference on Integrated Modelling for Asset Management. March 29-30, Kuala Lumpur, Malaysia. 
Wang, H. and Weng, D. (2014). Life-cycle cost assessment of seismically base-isolated large tanks in liquefied natural gas plants. Journal of Pressure Vessel Technologv 137(1). 011801 (7 pages).

Willis, W. I., Johnson, N. and Ranganathan, R. (1999). Costs and benefits of the E\&P MACT rule: application of a regulatory simulation model. In: SPE/EPA Exploration and Production Environmental Conference.1-3 March, Austin, Texas, USA. pp. 1-10.

Winkel, J.D. (1996). Use of life cycle costing in new and mature applications. European Production Operations Conference and Exhibition, April 16-17, Stavanger, Norway.

Wintle, J. and Sharp, J. (2008). Requirement for life extension of ageing offshore production installations. TWI Report No. 17554/08, prepared for Petroleum Safety Authority, Stavanger, Norway. 